\title{
Clinical and prognostic significance of preoperative plasma hyperfibrinogenemia in gallbladder cancer patients following surgical resection: a retrospective and in vitro study
}

Yi-Jun Shu ${ }^{1,2+}$, Hao Weng ${ }^{1,2+}$, Run-Fa Bao ${ }^{1,2+}$, Xiang-Song Wu $u^{1,2}$, Qian Ding ${ }^{1,2}$, Yang Cao ${ }^{1,2}$, Xu-An Wang ${ }^{1,2}$, Fei Zhang ${ }^{1,2}$, Shan-Shan Xiang ${ }^{1,2}$, Huai-Feng Li ${ }^{1,2}$, Mao-Lan Li ${ }^{1,2}$, Jia-Sheng Mu ${ }^{1,2}$, Wen-Guang $\mathrm{Wu}^{1,2}$ and Ying-Bin Liu ${ }^{1,2^{*}}$

\begin{abstract}
Background: Coagulation and fibrinolysis activation is frequently observed in cancer patients, and the tumors in these cases are thought to be associated with a higher risk of invasion, metastasis, and worse long-term outcome. The objective of this study was to elucidate the prognostic significance of blood coagulation tests and various clinicopathological characteristics in patients with gallbladder cancer (GBC) after surgical resection.

Methods: We retrospectively reviewed the medical records of 115 patients with histologically confirmed GBC who underwent surgical resection in our department. The prothrombin time (PT), activated partial thromboplastin time (aPTT), thrombin time (TT), international normalized ratio (INR), fibrinogen levels, and platelet counts were measured pretreatment at the time of diagnosis. The predictive value of fibrinogen levels for tumor staging was evaluated using a receiver operating characteristic (ROC) curve analysis. Correlations between the preoperative hyperfibrinogenemia and clinicopathological characteristics were analyzed, and univariate and multivariate survival analyses were performed to identify the factors associated with overall survival (OS). Cancer cell migration and invasion in vitro were examined to investigate the function of fibrinogen in GBC cell migration.
\end{abstract}

Results: The plasma levels for all coagulation tests, with the exception of INR, were significantly different between the GBC patients and control patients ( $p<0.001)$. Hyperfibrinogenemia $(>402 \mathrm{mg} / \mathrm{dL}$ ) was associated with poorly differentiated tumors, advanced tumor invasion, lymphatic metastasis, and advanced tumor stage $(p<0.001)$, and had a statistically significant adverse effect on survival $(p=0.001)$. In the multivariate analysis, hyperfibrinogenemia $(p=0.031)$ was independently associated with worse OS, tumor stage $(p=0.016)$, margin status $(p<0.001)$, and lymphatic metastasis $(p=0.035)$. Moreover, cell migration and invasion in vitro were significantly enhanced by fibrinogen.

Conclusions: Preoperative plasma fibrinogen levels was associated with tumor progression and may be an independent marker of poor prognosis in GBC patients. Furthermore, fibrinogen may contribute to cell migration by inducing epithelial-mesenchymal transition.

Keywords: Gallbladder cancer, Coagulation assays, Hyperfibrinogenemia, Prognosis

\footnotetext{
* Correspondence: liuybphd@126.com

${ }^{\dagger}$ Equal contributors

'Department of General Surgery and Laboratory of General Surgery, Xinhua Hospital, Affliated with Shanghai Jiao Tong University, School of Medicine, No.1665 Kongjiang Road, Shanghai 200092, China

${ }^{2}$ Institute of Biliary Tract Disease, Shanghai Jiao Tong University, School of Medicine, No. 1665 Kongjiang Road, Shanghai 200092, China
} 


\section{Background}

Gallbladder cancer (GBC) is the most common biliary tract malignancy and the seventh most common gastrointestinal cancer [1]. The Surveillance, Epidemiology, and End Results (SEER) program estimates the incidence of $\mathrm{GBC}$ at 2.5 per 100,000 persons. Despite the relatively low incidence rate, GBC-associated mortality is higher than that of other cancers [2]. The median survival of GBC patients is less than 1 year, which is due to early metastasis via lymphatic, perineural, and hematogenous routes, as well as direct invasion into the liver [3]. Although the tumor, node, and metastasis (TNM) staging system of the American Joint Committee on Cancer (AJCC) is the most widely used system, there is no worldwide consensus on the optimal system or marker for preoperatively predicting the prognosis of patients with GBC.

For more than one century, platelet and blood coagulation abnormalities have been described in cases of malignancy $[4,5]$, and several mechanisms have been proposed linking tumor biology to coagulation [6]. For example, patients with tumors in the lung, pancreas, and gastrointestinal tract are thought to be more prone to developing a hypercoagulable state [7].

Rather than serving as a mere trigger for increased thromboembolic events, cancer-induced hemostatic activity has been shown to promote tumor growth and cancer cell dissemination [8]. Both coagulation assays and high levels of circulating biomarkers, indicative of coagulation and fibrinolysis activation, have been associated with decreased survival in several tumor types [9-11]. Although previous studies evaluating the effect of combined anticoagulant treatment and chemotherapy in malignancy patients have observed survival benefits, sufficient evidence of such an advantage remains to be demonstrated. Nevertheless, understanding the potential pathways responsible for activated hemostatic and fibrinolytic activity may help identify surrogate markers for novel therapeutic targets.

Therefore, based on our previous basic study [12], the purpose of this study was to assess whether coagulation abnormalities are more frequently encountered in GBC and to delineate the correlation between coagulation function and other clinical variables. A long term study investigating the association between preoperative plasma fibrinogen levels and GBC patient survival has not yet been reported. In this current study, we evaluated the clinicopathological significance of hyperfibrinogenemia and its prognostic relevance for patients with GBC. Finally, we evaluated the relationship between fibrinogen and the migration of GBC cells in vitro.

\section{Methods \\ Ethics}

Written informed consent for surgical treatment and pathological examination was obtained from all patients according to institutional guidelines. All studies were approved by the Committee for Ethics of Xinhua Hospital, Shanghai Jiao Tong University School of Medicine.

\section{General information}

Between January 2010 and December 2013, 115 patients with histologically confirmed GBC underwent surgical resection at both our department and the sub-unit in Chongming, China. The median age at diagnosis was 67 years, the age range was 38-91 years, and females comprised the majority of the group $(n=78,67.8 \%)$. A total 88 patients $(76.5 \%)$ had associated biliary tract pathology, including gallstones in 76 patients and gallbladder polyps in 12 patients. Tumors that were histologically diagnosed after cholecystectomy were termed incidental GBC. In our study, the diagnosis of GBC in 12 patients $(10.4 \%)$ was missed at the time of routine cholecystectomy for gallstones. Well- or moderately differentiated adenocarcinoma was diagnosed in $64.4 \%$ of the tumors, and poorly differentiated adenocarcinoma was diagnosed in the other $35.7 \%$. The final disease staging and histological grading was based on the 7th edition of the AJCC manual [13]. Most of the lesions (74.8\%) were categorized as AJCC stage II, III, or IV at the time of diagnosis and treatment. Lymph node metastasis (42 cases) was recognized pathologically in $42.6 \%$ of the cases, and R0 resections were considered for resection with curative intent [14].

We excluded patients who had a history of malignancy or other simultaneous cancer, had undergone emergency surgery, had a history of heart attack or stroke, and were currently using anticoagulants, corticosteroids, estrogen, or aspirin, which may affect the hemostatic system. Additionally, 50 age- and sex-matched patients with benign disease (cholecystitis) were included in the analysis as a control group.

\section{Biochemical assays}

Venous blood samples were collected preoperatively into tubes containing sodium citrate, immediately centrifuged, and evaluated within $2 \mathrm{~h}$. The prothrombin time (PT), activated partial thromboplastin time (aPTT), thrombin time (TT), international normalized ratio (INR), and fibrinogen were measured with commercially available reagents for the kinetic nephelometric detection system using Diagon Dia-Timer 4 (Diagon Ltd, Budapest, Hungary).

\section{Surgical strategy and patient follow-up}

The surgical protocol for GBC at our center was as follows. For T1 lesions, curative resection was achieved by simple cholecystectomy; for T2-T4 lesions, radical surgery was performed with curative intent, comprising a liver wedge with a $2-\mathrm{cm}$ margin around the gallbladder and an enbloc GB resection with skeletonization of 
Table 1 The serum coagulation test results in patients with GBC and cholecystitis

\begin{tabular}{|c|c|c|c|}
\hline \multirow{2}{*}{$\begin{array}{l}\text { Coagulation } \\
\text { tests }\end{array}$} & \multirow{2}{*}{$\begin{array}{l}\text { Patients }(n=115) \\
\text { Mean } \\
\text { (standard } \\
\text { deviation) }\end{array}$} & \multirow{2}{*}{$\begin{array}{l}\text { Controls }(n=50) \\
\text { Mean } \\
\text { (standard } \\
\text { deviation) }\end{array}$} & \multirow[t]{2}{*}{$\mathbf{p}$} \\
\hline & & & \\
\hline PT (sec) & $11.6(1.3)$ & $10.5(1.1)$ & $<0.001$ \\
\hline aPTा (sec) & $27.8(4.7)$ & $32.2(4.3)$ & $<0.001$ \\
\hline$\Pi$ Tा (sec) & $15.4(3.4)$ & $13.8(1.5)$ & 0.002 \\
\hline INR & $1.1(0.9)$ & $1.0(0.1)$ & 0.325 \\
\hline Fibrinogen (mg/dL) & 407 (121) & $311(67)$ & $<0.001$ \\
\hline Platelets $\left(\times 10^{4} / \mathrm{mm}^{3}\right)$ & $221.7(73.4)$ & $188.2(55.3)$ & 0.013 \\
\hline
\end{tabular}

Bold italics indicate statistically significant values $(p<0.05)$ the hepatoduodenal ligament (lymph nodes along the hepatoduodenal ligament and common hepatic artery, and behind the pancreatic head). For these procedures, the "curettage and aspiration dissection technique" was performed using Peng's multifunctional operative dissector [15]. In cases where the GBC infiltrated the surrounding structures, including the common bile duct, omentum, and colon, combined resection of the invaded organ was performed to achieve a negative margin. For palliative surgery, a biliary T-tube drainage with $\mathrm{GBC}$ resection only was conducted in patients with distant metastasis, cachexia, or extensive lymph nodal involvement.

Table 2 Correlation between coagulation variables and clinicopathological characteristics in GBC patients

\begin{tabular}{|c|c|c|c|c|c|c|c|}
\hline \multirow[t]{2}{*}{ Variable } & \multirow[t]{2}{*}{$\mathbf{N}$} & \multicolumn{6}{|c|}{ Coagulation tests } \\
\hline & & PT (s) & aPTT (s) & $\mathrm{TT}(\mathrm{s})$ & INR & Fibrinogen (mg/dL) & PLT $\left(\times 10^{4} / \mathrm{mm}^{3}\right)$ \\
\hline \multicolumn{8}{|l|}{ Gender } \\
\hline Male & 37 (32.2\%) & $11.7(1.6)$ & $29.2(5.1)$ & $14.5(3.0)$ & $1.3(1.5)$ & $423.7(127.3)$ & $212.0(79.6)$ \\
\hline \multirow[t]{2}{*}{ Female } & $78(67.8 \%)$ & $11.6(1.2)$ & $27.2(4.4)$ & $15.8(3.6)$ & $1.0(0.1)$ & $398.2(118.0)$ & $226.3(69.6)$ \\
\hline & & $(p=0.642)$ & $(p=0.028)$ & $(p=0.126)$ & $(p=0.323)$ & $(p=0.293)$ & $(p=0.330)$ \\
\hline \multicolumn{8}{|l|}{ Age (years) } \\
\hline$<60$ & 29 (25.2\%) & $11.3(1.2)$ & $28.2(5.0)$ & $14.2(2.9)$ & $1.0(1.0)$ & $373.7(136.2)$ & $223.6(72.9)$ \\
\hline \multirow[t]{2}{*}{$\geq 60$} & $86(74.8 \%)$ & $11.7(1.4)$ & $27.7(4.6)$ & $15.8(3.5)$ & $1.1(1.0)$ & $417.5(114.3)$ & $221.1(73.4)$ \\
\hline & & $(p=0.123)$ & $(p=0.650)$ & $(p=0.651)$ & $(p=0.490)$ & $(p=0.653)$ & $(p=0.874)$ \\
\hline \multicolumn{8}{|c|}{ Histologic differentiation } \\
\hline Well & 15 (13.0\%) & $11.4(1.0)$ & $28.0(4.6)$ & $16.4(3.3)$ & $1.6(0.9)$ & 357.1 (86.4) & $214.7(61.6)$ \\
\hline Moderate & 59 (51.3\%) & $11.5(1.3)$ & $27.5(5.1)$ & $15.0(2.7)$ & $1.0(0.1)$ & $381.5(116.3)$ & $214.9(74.1)$ \\
\hline Poor & $40(34.8 \%)$ & $11.7(1.4)$ & $28.0(4.1)$ & $15.3(4.2)$ & $1.1(0.1)$ & $454.3(116.6)$ & $231.0(73.5)$ \\
\hline \multirow[t]{2}{*}{ Undifferentiated } & $1(0.9 \%)$ & & & & & & \\
\hline & & $(p=0.593)$ & $(p=0.842)$ & $(p=0.480)$ & $(p=0.060)^{*}$ & $(p=0.002)^{* *}$ & $(p=0.526)$ \\
\hline \multicolumn{8}{|l|}{ Tumor invasion } \\
\hline Tis- $_{1}$ & $18(0.2 \%)$ & $11.9(1.5)$ & $28.7(5.1)$ & $17.0(3.2)$ & $1.0(0.1)$ & $349.9(68.7)$ & $210.6(63.9)$ \\
\hline $\mathrm{T}_{2}-\mathrm{T}_{4}$ & $95(0.8 \%)$ & $11.5(1.3)$ & $27.8(4.7)$ & $14.9(3.4)$ & $1.1(1.0)$ & $421.9(127.1)$ & $223.1(75.0)$ \\
\hline \multirow[t]{2}{*}{ Not available } & $2(0.0 \%)$ & & & & & & \\
\hline & & $(p=0.262)$ & $(p=0.423)$ & $(p=0.038)$ & $(p=0.643)$ & $(p=0.016)$ & $(p=0.509)$ \\
\hline \multicolumn{8}{|c|}{ Lymph node metastasis } \\
\hline Absent & $73(63.5 \%)$ & $11.6(1.3)$ & $27.8(4.8)$ & $15.7(3.2)$ & $1.2(1.1)$ & $382.7(116.0)$ & $208.5(64.5)$ \\
\hline \multirow[t]{2}{*}{ Present } & $42(36.5 \%)$ & $11.5(1.5)$ & $27.9(4.6)$ & $14.7(3.8)$ & $1.0(0.1)$ & $447.7(120.0)$ & $244.7(81.4)$ \\
\hline & & $(p=0.759)$ & $(p=0.917)$ & $(p=0.223)$ & $(p=0.524)$ & $(p=0.005)$ & $(p=0.010)$ \\
\hline \multicolumn{8}{|l|}{ TNM stage } \\
\hline $0-1$ & $22(19.1 \%)$ & $11.9(1.3)$ & $27.7(5.1)$ & $16.9(3.2)$ & $1.0(0.1)$ & $331.4(86.3)$ & $208.6(67.0)$ \\
\hline \multirow[t]{2}{*}{ II-IV } & 93 (80.9\%) & $11.5(1.3)$ & $27.9(4.6)$ & $14.9(3.4)$ & $1.1(1.0)$ & $432.9(120.9)$ & $224.8(74.3)$ \\
\hline & & $(p=0.260)$ & $(p=0.891)$ & $(p=0.057)$ & $(p=0.616)$ & $(p<0.001)$ & $(p=0.353)$ \\
\hline
\end{tabular}

GBC, gallbladder carcinoma; PT, prothrombin time; aPTT, activated partial prothromboplastin time; TT, thrombin time; INR, international normalized ratio; PLT, platelets. Bold italics indicate statistically significant values $(p<0.05)$.

*For Well vs. Moderate, $\mathrm{p}=0.021$; Moderate vs. Poor, $\mathrm{p}=0.870$; Well vs. Poor, $\mathrm{p}=0.036$.

**For Well vs. Moderate, $p=0.458$; Moderate vs. Poor, $p=0.002$; Well vs. Poor, $p=0.005$. 
Patients were followed postoperatively every 3 months for 2 years and then every 6 months thereafter. The date of surgery marked the beginning of the follow-up period, which ended at the last follow-up visit (December 2013) or death.

\section{Cell lines and culture}

The human gallbladder cancer cell lines GBC-SD and NOZ were purchased from the Shanghai Cell Institute Country Cell Bank. GBC-SD cells were cultured in highglucose Dulbecco's modified eagle's medium (DMEM) (Gibco, California, USA), and NOZ cells were cultured in William's medium (Gibco) supplemented with $10 \%$ fetal bovine serum (Gibco), $100 \mu \mathrm{g} / \mathrm{mL}$ streptomycin, and 100 $\mathrm{U} / \mathrm{mL}$ penicillin (Hyclone, Logan, UT) at $37^{\circ} \mathrm{C}$ in an atmosphere containing $5.0 \% \mathrm{CO}_{2}$. Cells were routinely grown in 100-mm plastic tissue culture dishes (Corning, New York, USA) and harvested using a trypsin-EDTA solution when they reached the logarithmic growth phase. Cells were maintained in these culture conditions for all experiments.

\section{Cell migration and invasion assays}

For the in vitro wound-healing assay, a cell-free area of the culture medium was wounded by scratching with a $200-\mu \mathrm{L}$ pipette tip. Cell migration into the wound area was monitored in a serum-free medium and photographed using a fluorescence microscope at 0,24, and $48 \mathrm{~h}$. Then, the effects of fibrinogen (Sigma, St. Louis, MO) on cell migration and invasion were determined using 8- $\mu \mathrm{m}$ transwell filters (BD Biosciences, Franklin Lakes, NJ, USA) with or without Matrigel (BD). GBC-SD $\left(3 \times 10^{4}\right)$ and NOZ $\left(4 \times 10^{4}\right)$ cells in $0.5 \mu \mathrm{L}$ of serum-free DMEM and William's media were added to the upper chamber, which contained a noncoated/Matrigel-coated membrane. The same protocol was performed on the treatment group ( $40 \mu \mathrm{g} / \mathrm{mL}$ fibrinogen). The lower chamber was filled with $500 \mu \mathrm{L}$ of basal medium comprising $10 \%$ fetal bovine serum. After a 24-h incubation at $37^{\circ} \mathrm{C}$ in a $5 \% \mathrm{CO}_{2}$ humidified incubator, cells that migrated to the lower compartment were fixed with methanol and stained with crystal violet. Migrated or invaded cells were counted in five randomly chosen fields in each well, and imaging and cell counting were performed at $10 \times$ magnification

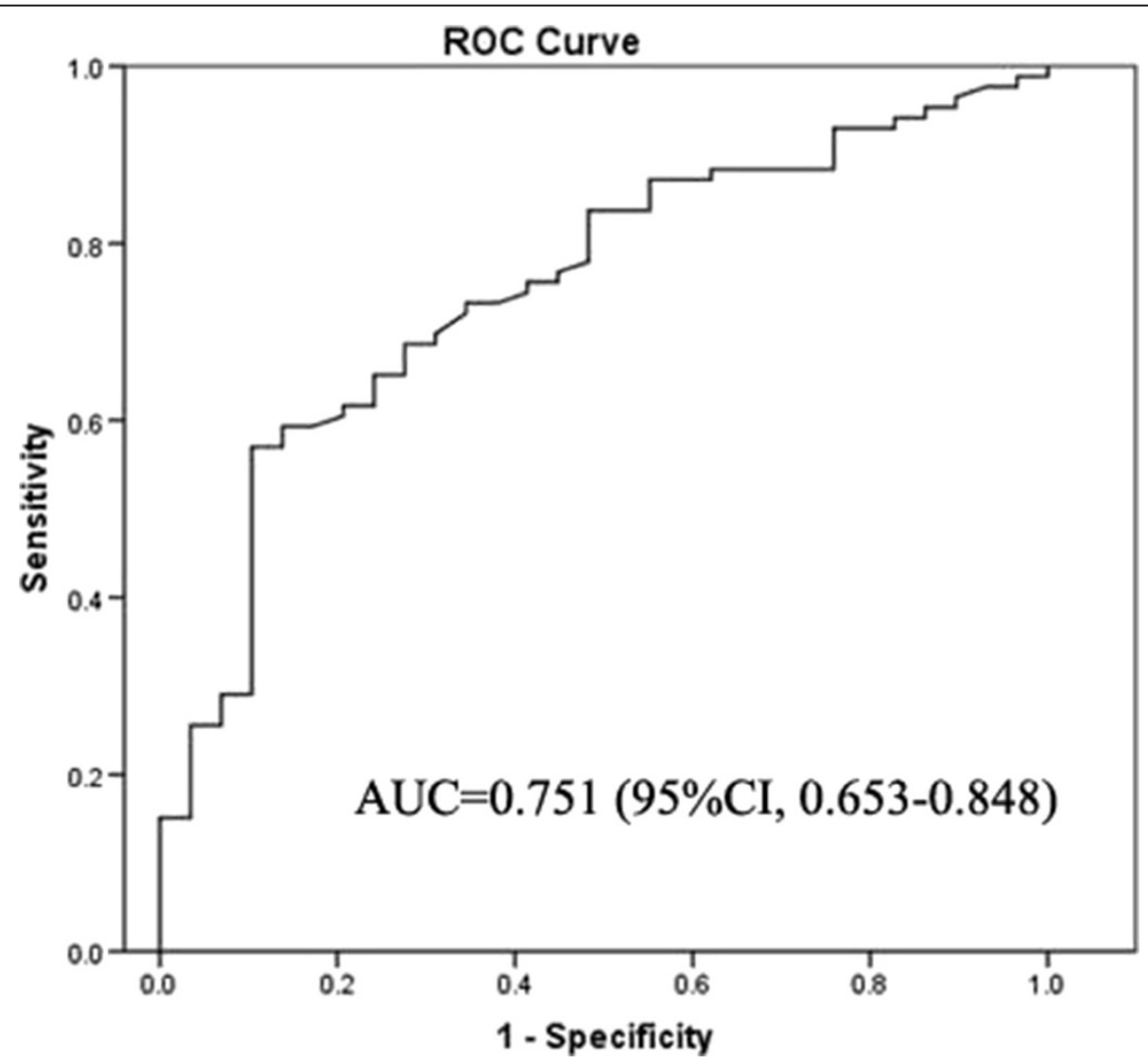

Figure 1 Receiver operating characteristic (ROC) curve analysis to predict GBC stage. The area under the ROC curve (AUC) indicates the diagnostic power of preoperative plasma fibrinogen levels. 
using a fluorescence microscope. The experiments were performed in triplicate.

\section{Western blot analysis}

Cells $\left(1 \times 10^{7}\right)$ were seeded into a cell culture dish and treated with fibrinogen $(20$ or $40 \mu \mathrm{g} / \mathrm{mL})$ for $48 \mathrm{~h}$. Cellular proteins were extracted using lysis buffer (Beyotime, Shanghai, China) from the control and treated cells. For western blot analysis, the proteins were separated by SDS-PAGE and blotted onto PVDF membranes. The membrane was blocked in blocking buffer ( $5 \%$ non-fat dry milk) for $1 \mathrm{~h}$ at room temperature and incubated with primary antibodies in blocking buffer overnight at $4^{\circ} \mathrm{C}$. Anti-E-cadherin and anti-vimentin (both at 1:500, Cell Signaling Technology, Danvers, USA) were used as primary antibodies. $\beta$-Actin (Beyotime) was used as a loading control. The blot was then incubated with the appropriate secondary antibody, detected with $10 \mathrm{~mL}$ of AP buffer at room temperature for $10-20 \mathrm{~min}$, and photographed. The optical densities of the bands were scanned and quantified using the Gel Doc 2000 (BioRad, Hercules, USA).

\section{Quantitative real-time PCR (qRT-PCR)}

Total RNA was extracted from control and treated cells using Trizol reagent (Takara, Shiga, Japan), and the firststrand cDNA was synthesized from $2 \mu \mathrm{g}$ of total RNA using random primers and the M-MLV Reverse Transcriptase (Invitrogen, Carlsbad, CA). RNA expression was measured by qRT-PCR using the SYBR-Green method (Takara) according to the manufacturer's instructions. Primer sequences were as follows: E-cadherin, forward primer 5'-TGCCCAGAAAATGAAAAAGG-3', reverse primer 5'-GTGTAYGTGGCAATGCGTTC-3'; vimentin, forward primer $5^{\prime}$-GAGAACTTTGCCGTTG AAGC-3', reverse primer 5'-GCTTCCTGTAGGTGGC AATC-3'; GADPH, forward primer 5'-GAGAGACCCT CACTGCTG-3', reverse primer 5' -GASTGGTAGATGA CAAGGTGC-3'. Differences in expression were assessed by $2^{-\Delta \Delta \mathrm{Ct}}$ relative quantitative analysis.

\section{Statistical analysis}

Continuous variables are presented as the mean (standard deviation), and categorical variables are presented as the frequency and proportion (\%). The relationships between coagulation tests, including PT, aPTT, TT, INR, fibrinogen, and clinicopathological characteristics, were evaluated and compared using the unpaired $t$-test and one-way analysis of variance. The predictive performance of fibrinogen levels for tumor staging was evaluated using a receiver operating characteristic (ROC) curve analysis. The positive predictive value (PPV) was calculated using a cut-off value selected from the ROC curve. The association between hyperfibrinogenemia and various
Table 3 Demographic characteristics of GBC patients with and without hyperfibrinogenemia

\begin{tabular}{|c|c|c|c|}
\hline \multirow[t]{2}{*}{ Variables } & \multicolumn{2}{|c|}{$\begin{array}{l}\text { Plasma fibrinogen levels } \\
(\mathrm{mg} / \mathrm{dL})\end{array}$} & \multirow[t]{2}{*}{$p^{a}$} \\
\hline & $\begin{array}{c}\leq 402 \\
(n=6052.2 \%)\end{array}$ & $\begin{array}{c}>402 \\
(n=5547.8 \%)\end{array}$ & \\
\hline \multicolumn{4}{|l|}{ Gender } \\
\hline Male & $14(12.2 \%)$ & $23(20 \%)$ & 0.034 \\
\hline Female & $46(40 \%)$ & $32(27.8 \%)$ & \\
\hline \multicolumn{4}{|l|}{ Age } \\
\hline$<60$ years & 19 (16.5\%) & $10(8.7 \%)$ & 0.096 \\
\hline$\geq 60$ years & $41(35.7 \%)$ & $45(39.1 \%)$ & \\
\hline Incidental GBC & $16(13.9 \%)$ & $9(7.8 \%)$ & 0.181 \\
\hline \multicolumn{4}{|l|}{ Associated gallstone } \\
\hline Absent & $18(15.7 \%)$ & $21(18.3 \%)$ & 0.355 \\
\hline Present & $42(36.5 \%)$ & $34(29.6 \%)$ & \\
\hline \multicolumn{4}{|l|}{ Liver function } \\
\hline ALT & $63.9 \pm 160.8$ & $89.0 \pm 148.5$ & 0.439 \\
\hline AST & $48.3 \pm 99.8$ & $63.9 \pm 106.0$ & 0.471 \\
\hline Serum total bilirubin $(\mathrm{mg} / \mathrm{dL})$ & $23.7 \pm 44.4$ & $54.3 \pm 95.1$ & 0.056 \\
\hline Albumin (g/dL) & $39.5 \pm 4.6$ & $37.4 \pm 4.9$ & 0.04 \\
\hline Hemoglobin (g/dL) & $128.7 \pm 15.3$ & $122.7 \pm 19.5$ & 0.087 \\
\hline Platelet count $\left(\times 10^{4} / \mathrm{mm}^{3}\right)$ & $209.3 \pm 63.1$ & $235.3 \pm 80.7$ & 0.056 \\
\hline WBC count $\left(\times 10^{9} / \mathrm{mm}^{3}\right)$ & $6.85 \pm 3.84$ & $8.30 \pm 3.45$ & 0.048 \\
\hline CA19-9 (U/mL) & $131.6 \pm 263.7$ & $474.1 \pm 370.9$ & 0.132 \\
\hline CEA (ng/mL) & $6.3 \pm 21.7$ & $13.4 \pm 47.6$ & 0.358 \\
\hline CA125 (U/mL) & $35.3 \pm 55.8$ & $95.1 \pm 141.6$ & 0.025 \\
\hline Histologic differentiation & & & $<0.001$ \\
\hline Well & $11(9.6 \%)$ & $4(3.5 \%)$ & \\
\hline Moderate & $38(33.0 \%)$ & $21(18.3 \%)$ & \\
\hline Poor & 11 (9.6\%) & $29(25.2 \%)$ & \\
\hline Undifferentiated & $1(0.9 \%)$ & & \\
\hline \multicolumn{4}{|l|}{ Tumor invasion } \\
\hline Tis- $_{1}$ & 15 (13.0\%) & $5(4.4 \%)$ & 0.019 \\
\hline $\mathrm{T}_{2}-\mathrm{T}_{4}$ & $42(36.5 \%)$ & 49 (42.6\%) & \\
\hline Not available & $3(2.6 \%)$ & $1(0.9 \%)$ & \\
\hline \multicolumn{4}{|l|}{ Lymph node metastasis } \\
\hline Absent & $48(41.7 \%)$ & $25(21.7 \%)$ & $<0.001$ \\
\hline Present & $12(10.4 \%)$ & $30(26.1 \%)$ & \\
\hline \multicolumn{4}{|l|}{ TNM stage } \\
\hline $0-1$ & $25(21.7 \%)$ & $4(3.5 \%)$ & $<0.001$ \\
\hline II-IV & 35 (30.4\%) & $51(44.4 \%)$ & \\
\hline
\end{tabular}

Bold italics indicate statistically significant values $(p<0.05)$.

$\mathrm{GBC}$, gallbladder carcinoma; ALT, alanine aminotransferase; $\mathrm{AST}$, aspartate aminotransferase; WBC, white blood cell count; CA, carbohydrate antigen; CEA, carcinoembryonic antigen; TNM, tumor, node, metastasis classification system; CBD, common bile duct.

${ }^{a} X^{2}$ test or Student's $t$ test. 
Table 4 Univariate analysis of overall survival in GBC patients

\begin{tabular}{|c|c|c|c|c|c|}
\hline Variables & Characteristics & $\mathrm{n}$ & Median OS (months) & HR (95\% CI) & $p$ value \\
\hline \multirow[t]{2}{*}{ Gender } & Male & 37 & 14 & $1.23(0.76,2.01)$ & 0.392 \\
\hline & Female & 78 & 11 & & \\
\hline \multirow[t]{2}{*}{ Age } & $\leq 60$ years & 29 & 16 & $0.66(0.38,1.13)$ & 0.122 \\
\hline & $>60$ years & 86 & 11 & & \\
\hline \multirow[t]{2}{*}{ Associated gallstone } & Absent & 39 & 13 & $0.68(0.43,1.09)$ & 0.105 \\
\hline & Present & 76 & 12 & & \\
\hline \multirow[t]{2}{*}{ ALT } & $\leq 75 \mathrm{U} / \mathrm{L}$ & 85 & 12 & $1.35(0.75,2.41)$ & 0.315 \\
\hline & $>75 \mathrm{U} / \mathrm{L}$ & 32 & 10 & & \\
\hline \multirow[t]{2}{*}{ AST } & $\leq 38 \mathrm{U} / \mathrm{L}$ & 78 & 13 & $1.24(0.72,2.13)$ & 0.437 \\
\hline & $>38 \mathrm{U} / \mathrm{L}$ & 37 & 11 & & \\
\hline \multirow[t]{2}{*}{ Serum total bilirubin } & $\leq 12 \mathrm{mg} / \mathrm{dL}$ & 60 & 14 & $1.50(0.91,2.45)$ & 0.107 \\
\hline & $>12 \mathrm{mg} / \mathrm{dL}$ & 55 & 10 & & \\
\hline \multirow[t]{2}{*}{ Albumin } & $<35 \mathrm{~g} / \mathrm{dL}$ & 29 & 11 & $0.82(0.45,1.48)$ & 0.506 \\
\hline & $\geq 35 \mathrm{~g} / \mathrm{dL}$ & 86 & 12 & & \\
\hline \multirow[t]{2}{*}{ Hemoglobin } & $\leq 125 \mathrm{~g} / \mathrm{dL}$ & 53 & 10 & $0.54(0.34,0.88)$ & 0.012 \\
\hline & $>125 \mathrm{~g} / \mathrm{dL}$ & 49 & 15 & & \\
\hline \multirow[t]{2}{*}{ WBC count } & $\leq 6.8 \times 10^{3} / \mathrm{mm}^{3}$ & 57 & 15 & $1.65(1.03,2.64)$ & 0.035 \\
\hline & $>6.8 \times 10^{3} / \mathrm{mm}^{3}$ & 45 & 9 & & \\
\hline \multirow[t]{2}{*}{ Fibrinogen } & $\leq 402 \mathrm{mg} / \mathrm{dL}$ & 60 & 17 & $0.48(0.31,0.75)$ & 0.001 \\
\hline & $>402$ mg/dL & 55 & 8 & & \\
\hline \multirow[t]{2}{*}{ Platelet count } & $\leq 215 \times 10^{4} / \mathrm{mm}^{3}$ & 58 & 13 & $1.44(0.92,2.24)$ & 0.108 \\
\hline & $>215 \times 10^{4} / \mathrm{mm}^{3}$ & 57 & 11 & & \\
\hline \multirow[t]{2}{*}{ CA19-9 } & $\leq 35 \mathrm{U} / \mathrm{mL}$ & 54 & 13 & $1.36(0.82,2.25)$ & 0.239 \\
\hline & $>35 \mathrm{U} / \mathrm{mL}$ & 61 & 10 & & \\
\hline \multirow[t]{2}{*}{ CEA } & $\leq 10 \mathrm{ng} / \mathrm{mL}$ & 62 & 13 & $1.61(0.94,2.76)$ & 0.078 \\
\hline & $>10 \mathrm{ng} / \mathrm{mL}$ & 53 & 11 & & \\
\hline \multirow[t]{2}{*}{ CA125 } & $\leq 35 \mathrm{U} / \mathrm{mL}$ & 66 & 12 & $1.60(0.89,2.88)$ & 0.11 \\
\hline & $>35 \mathrm{U} / \mathrm{mL}$ & 49 & 11 & & \\
\hline \multirow[t]{3}{*}{ Histologic differentiation } & Well & 15 & 32 & $0.51(0.36,0.72)$ & $<0.001$ \\
\hline & Moderate & 59 & 13 & & \\
\hline & Poor and undifferentiated & 41 & 8 & & \\
\hline \multirow[t]{2}{*}{ Tumor invasion } & Tis and $T_{1}$ & 20 & 32 & $4.58(2.15,9.76)$ & $<0.001$ \\
\hline & $\mathrm{T}_{2}, \mathrm{~T}_{3}$ and $\mathrm{T}_{4}$ & 91 & 11 & & \\
\hline \multirow[t]{2}{*}{ Lymph node metastasis } & Absent & 73 & 17 & $4.08(2.49,6.67)$ & $<0.001$ \\
\hline & Present & 42 & 7 & & \\
\hline \multirow[t]{2}{*}{ TNM stage } & 0 and $I$ & 29 & 33 & $5.97(2.78,12.82)$ & $<0.001$ \\
\hline & II and IV & 86 & 11 & & \\
\hline \multirow[t]{2}{*}{ Margin status } & RO & 69 & 20 & $0.14(0.09,0.24)$ & $<0.001$ \\
\hline & R1 & 46 & 6 & & \\
\hline \multirow[t]{2}{*}{ Combined hepatectomy } & No & 51 & 11 & $0.94(0.59,1.49)$ & 0.792 \\
\hline & Yes & 54 & 12 & & \\
\hline
\end{tabular}


Table 4 Univariate analysis of overall survival in GBC patients (Continued)

\begin{tabular}{lllll}
\hline Combined CBD resection & No & $\mathbf{8 7}$ & $\mathbf{1 4}$ & $\mathbf{2 . 0 6}(\mathbf{1 . 1 5}, \mathbf{3 . 6 9 )}$ \\
& Yes & $\mathbf{1 8}$ & $\mathbf{9}$ & $\mathbf{0 . 0 1 3}$ \\
\multirow{2}{*}{ Lymphadenectomy } & No & 15 & 8 & $\mathbf{1 . 8 9}(\mathbf{1 . 0 1 , 3 . 5 6 )}$ \\
& Yes & 83 & 12 & $\mathbf{0 . 0 4 4}$ \\
\hline
\end{tabular}

GBC, gallbladder carcinoma; OS, overall survival; $\mathrm{HR}$, hazard ratio; $\mathrm{Cl}$, confidence interval; $\mathrm{ALT}$, alanine aminotransferase; $\mathrm{AST}$, aspartate aminotransferase; WBC, white blood cell count; CA, carbohydrate antigen; CEA, carcinoembryonic antigen; TNM, tumor, node, metastasis classification system; CBD, common bile duct. Bold italics indicate statistically significant values $(p<0.05)$.

clinicopathological factors was assessed using Fisher's exact test. The 1- and 3-year survival rates were calculated using Kaplan-Meier analysis and compared using the logrank test. Variables with p-values $<0.05$ on the univariate analysis were included in the final multivariate survival analysis that was conducted using the Cox proportional hazards model. Statistical significance was designated at $\mathrm{p}<0.05$. Statistical analysis was performed using SPSS 19.0 software.

\section{Results}

\section{Comparison of coagulation tests between GBC patients} and cholecystitis controls

The plasma levels for all coagulation tests, including PT, aPTT, TT, fibrinogen, and platelet counts, were significantly different between the GBC patients and cholecystitis controls $(\mathrm{p}<0.05$, Table 1$)$. This result suggested a higher tendency for an activated coagulation cascade in patients with malignancy compared with those with benign inflammation.

\section{Correlations between coagulation tests and clinical variables}

The relationships between coagulation variables and tumor progression, including histologic differentiation, tumor invasion, lymph node metastasis, TNM stage, and clinical characteristics of the patients, are summarized in Table 2. A statistically significant association was observed between the preoperative plasma fibrinogen levels and tumor differentiation of GBC; specifically, GBC patients showing poor differentiation exhibited higher plasma fibrinogen levels compared with patients with moderate and well-differentiated tumors $(\mathrm{p}=0.002)$. More severe GBC stages, including tumor invasion, lymph node

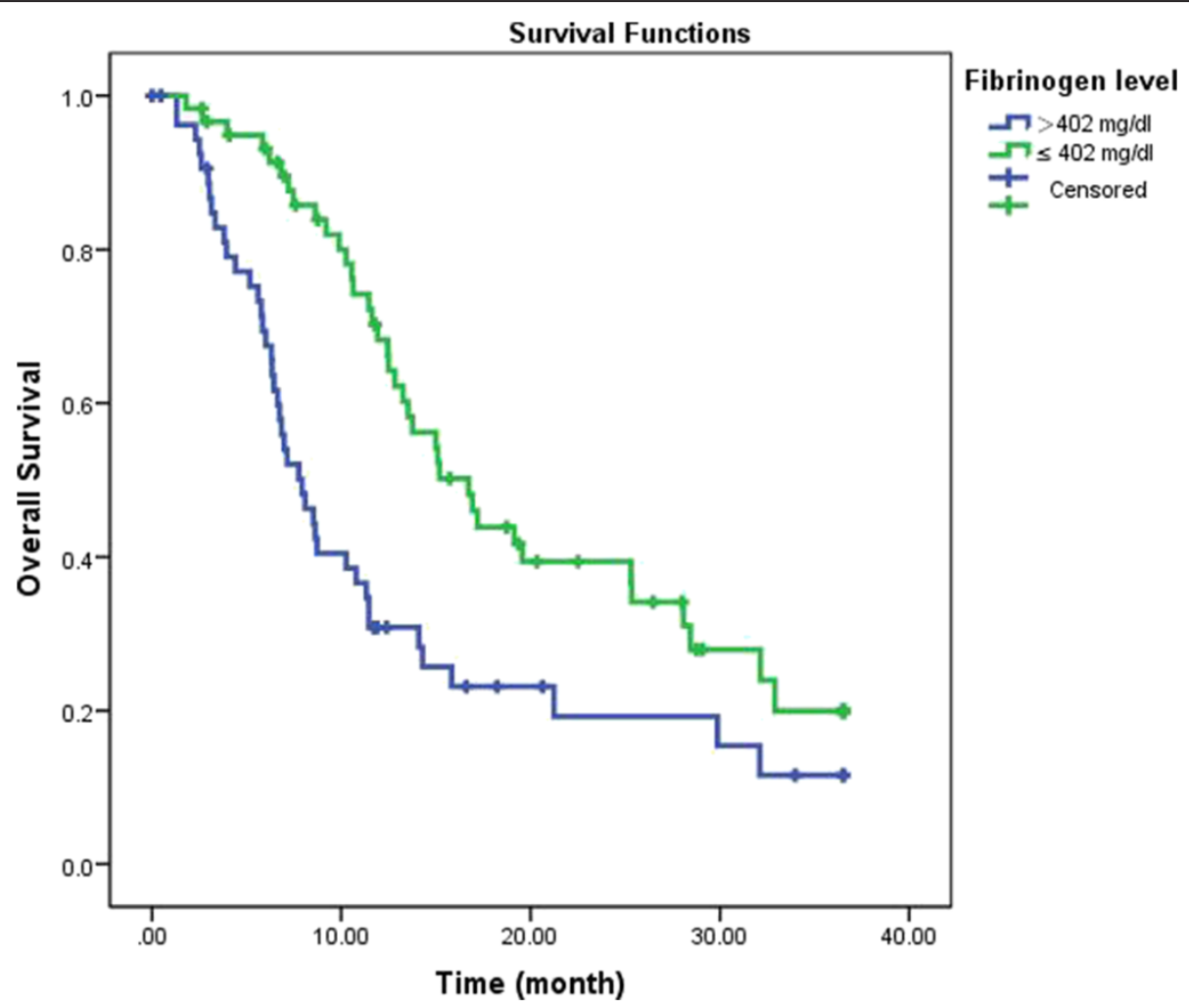

Figure 2 Survival curve according to the presence of preoperative hyperfibrinogenemia. Data compares hyperfibrinogenemia vs. non-hyperfibrinogenemia patients $(p=0.001)$. 
metastasis, and TNM stage, were also associated with higher fibrinogen levels compared with limited-stage disease (tumor invasion, $\mathrm{p}=0.016$; $\mathrm{LN}$ metastasis, $\mathrm{p}=0.005$; and TNM stage, $\mathrm{p}<0.001)$.

\section{Diagnostic performance of preoperative plasma fibrinogen levels for tumor staging in GBC patients}

With the fibrinogen levels correlating with TNM stage, the diagnostic performance of fibrinogen for tumor staging in patients with $\mathrm{GBC}$ was further investigated. We found that the area under the ROC curve (AUC) of the fibrinogen levels was 0.751 (95\% CI: 0.65-0.85, Figure 1).

The optimal cut-off value for the fibrinogen concentration (402 mg/dL) was selected based on an ROC curve analysis; thus, plasma fibrinogen levels $>402 \mathrm{mg} / \mathrm{dL}$ were defined as hyperfibrinogenemia. At a $402 \mathrm{mg} / \mathrm{dL}$ cut-off, the fibrinogen concentration had a PPV of $92.73 \%$, suggesting that hyperfibrinogenemia may be a valuable biomarker for predicting advanced GBC.

\section{Correlations between preoperative hyperfibrinogenemia and clinicopathological characteristics}

Because the frequency of hyperfibrinogenemia was much higher in patients with malignancy $(18.3 \%$ in cholecystitis controls vs. $47.8 \%$ in GBC patients; $\chi^{2}=14.60$, $\mathrm{p}<0.001$ ), we grouped the clinicopathological factors of the 115 GBC patients according to the presence or absence of preoperative hyperfibrinogenemia. As shown in Table 3, preoperative hyperfibrinogenemia was significantly correlated with histological differentiation $(\mathrm{p}<0.001)$, tumor invasion $(\mathrm{p}=0.019)$, nodal metastasis $(\mathrm{p}<0.001)$, and TNM stage $(\mathrm{p}<0.001)$.

\section{Survival analysis}

The median follow-up time was 16 months (range, 1-36 months). Six patients (5.2\%) were lost to follow-up, and the median survival time for all patients was 12.5 months (95\% CI, 10.44-14.49 months). During the follow-up period, 79 patients $(68.7 \%)$ died owing to disease-related factors.

Evaluation of the effect of clinical variables confirmed the negative impact of advanced tumor stage, including poor differentiation, deeper tumor invasion, presence of lymph node metastasis, and TNM stage II-IV, and surgery assessment, including R1 resection, absence of lymphadenectomy, (lymphadenectomy $\mathrm{p}=0.044$; all other variables $\mathrm{p}<0.001$; Table 4). Among the laboratory variables examined, low hemoglobin and elevated leukocyte concentrations were associated with significantly worse outcomes when compared with concentrations below the median range $(\mathrm{p}=0.012$ and $\mathrm{p}=0.035$, respectively). Moreover, the survival of patients with preoperative hyperfibrinogenemia was significantly worse than that of patients without hyperfibrinogenemia $(p=0.001$, Figure 2$)$. The actual 1- and 3-year survival rates for patients with hyperfibrinogenemia were 30.8 and $11.6 \%$, respectively, whereas these rates were 68.2 and $34.1 \%$, respectively, for patients without preoperative hyperfibrinogenemia.

Multivariate analyses were performed using Cox's proportional hazards regression. Prognostically significant variables $(\mathrm{p}<0.05)$, including plasma hemoglobin, fibrinogen levels, leukocyte counts, histologic differentiation, tumor invasion, lymph node metastasis, TNM stage, margin status, and lymphadenectomy, were included in the analysis. The results indicated that only stages II-IV, lymph node metastasis, preoperative hyperfibrinogenemia, and R1 resection were independently associated with decreased survival (Table 5).

\section{Fibrinogen stimulation of GBC metastasis and invasion in vitro}

Based on the above results, we concluded that fibrinogen is closely associated with GBC invasion and metastasis. To further explore the role of fibrinogen in the GBC cell lines, we obtained fibrinogen from human plasma. As shown in Figure $3 \mathrm{~A}$ and $\mathrm{B}$, the woundinghealing and transwell migration assays revealed enhanced migration and invasion of GBC-SD and NOZ cells in the presence of fibrinogen, suggesting that fibrinogen from human plasma may significantly promote the metastasis of GBC cells in vitro. Moreover, both western blot analysis and qRT-PCR showed that fibrinogen increased the expression of the mesenchymal marker vimentin, but the epithelial marker E-cadherin expression decreased (Figure $3 \mathrm{C}$ and $\mathrm{D}$ ), indicating that EMT signaling may contribute to the enhanced migration caused by hyperfibrinogenemia. Collectively, our data demonstrate that fibrinogen plays a role in promoting cell metastasis in vitro.

\section{Discussion}

Systematic activation of the clotting system has been observed in cancer patients, typically reflected in subclinical

Table 5 Multivariate analysis for overall survival in GBC patients

\begin{tabular}{lll}
\hline Variables & OS HR $(\mathbf{9 5} \% \mathrm{Cl})$ & $\mathbf{p}$ value \\
\hline TNM stage & $17.42(1.71,177.56)$ & 0.016 \\
0-I vs. II-IV & $2.15(1.06,4.40)$ & 0.035 \\
$\begin{array}{l}\text { Lymph node metastasis } \\
\text { Absent and not available vs. Present }\end{array}$ & $0.52(0.29,0.94)$ & 0.031 \\
$\begin{array}{l}\text { Fibrinogen } \\
\leq 402 \mathrm{mg} / \mathrm{dL} \text { vs. }>402 \mathrm{mg} / \mathrm{dL}\end{array}$ & $0.15(0.07,0.31)$ & $<0.001$ \\
$\begin{array}{l}\text { Margin status } \\
\text { R0 vs. R1 }\end{array}$ & \\
\hline
\end{tabular}

$\mathrm{GBC}$, gallbladder carcinoma; OS. overall survival; $\mathrm{HR}$, hazard ratio; $\mathrm{Cl}$, confidence interval. 

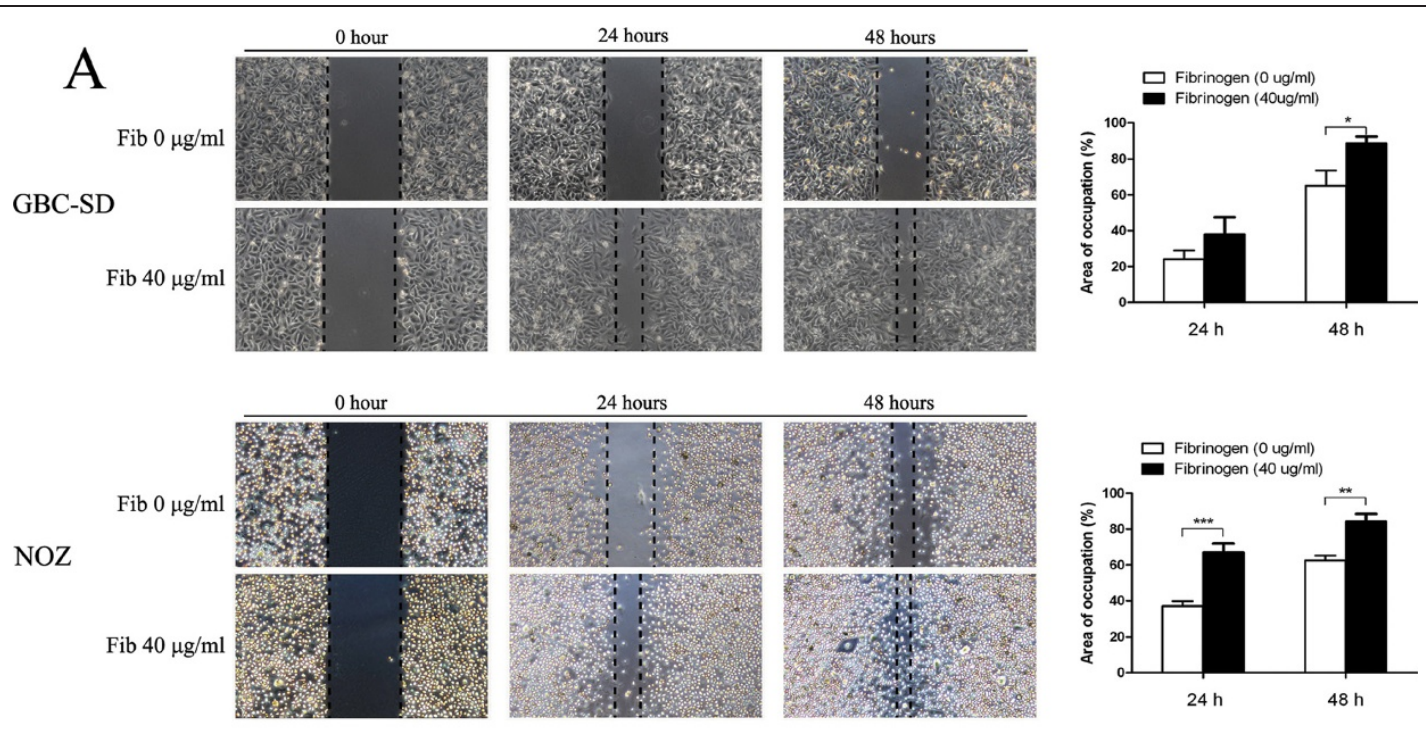

\section{B}

GBC-SD

$\mathrm{NOZ}$
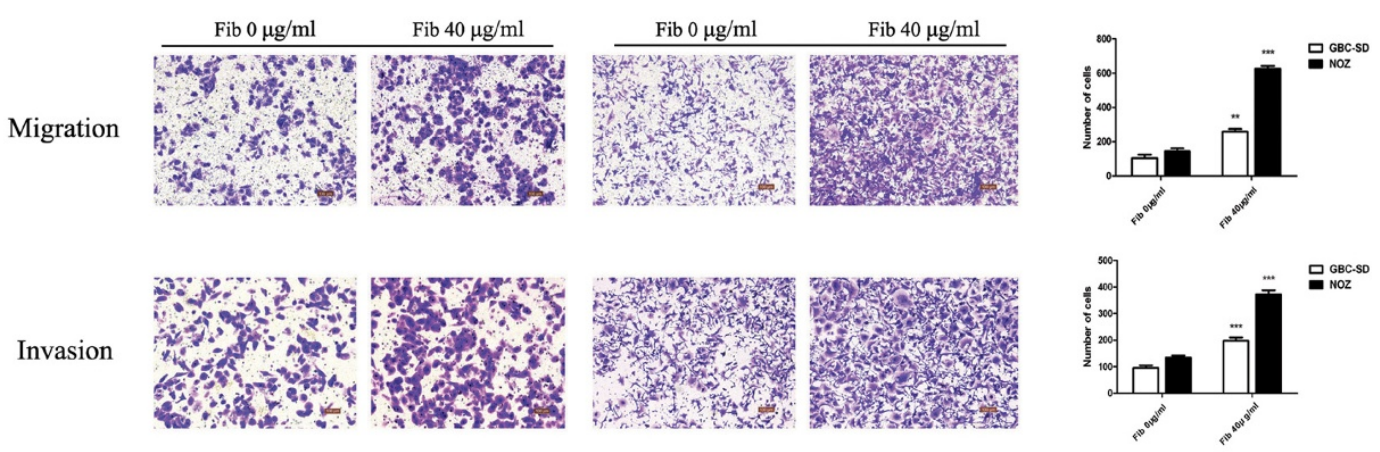

C

$\mathrm{Fib}(\mu \mathrm{g} / \mathrm{ml})$

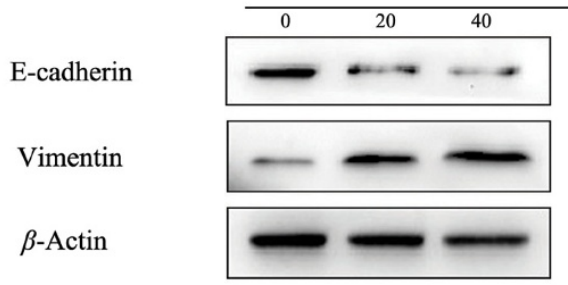

GBC-SD

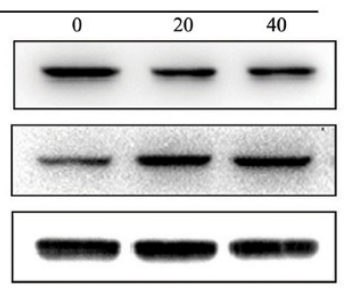

$\mathrm{NOZ}$

D
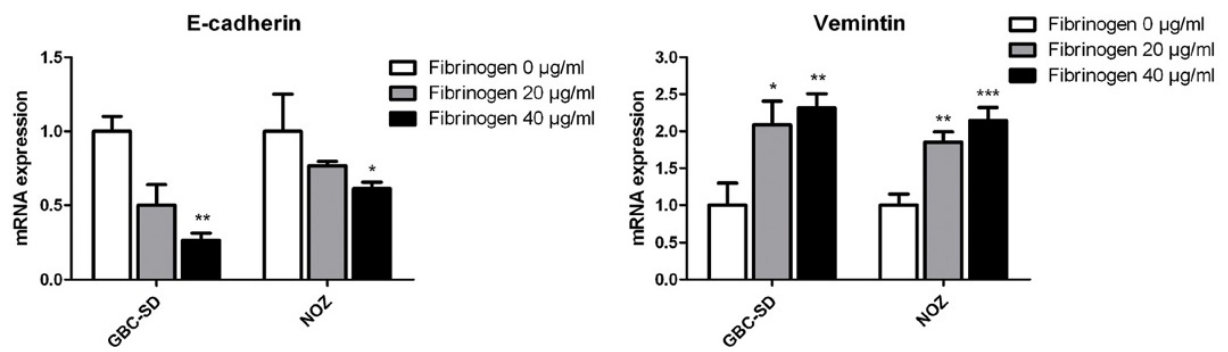

Figure $\mathbf{3}$ (See legend on next page.) 
(See figure on previous page.)

Figure 3 Fibrinogen stimulation of GBC metastasis and invasion in vitro. (A) The effect of fibrinogen on the migration of GBC-SD and NOZ cells. The area of the GBC-SD and NOZ cell monolayers treated with fibrinogen $(40 \mu \mathrm{g} / \mathrm{mL})$ increased 24 and $48 \mathrm{~h}$ after scratching the media. The histogram shows that fibrinogen significantly improved the migration of GBC-SD and NOZ cells. (B) Transwell migration and invasion assays were performed after treating the GBC-SD and NOZ cell lines, with fibrinogen $(40 \mu \mathrm{g} / \mathrm{mL})$, which is summarized in the histograms. (C and D) Biomarkers for EMT: E-cadherin and vimentin were analyzed by western blotting and qRT-PCR. All graphs indicate the mean \pm SD. Statistical significance as follows: ${ }^{*} p<0.05,{ }^{* *} p<0.01$, and ${ }^{* * *} p<0.001$.

abnormalities on conventional coagulation tests [16,17]. Despite numerous studies investigating the causes of hypercoagulability and thromboembolic complications in patients suffering from malignancy, the responsible mechanisms remain poorly understood [18]. Some evidence suggests that activation of the coagulation and fibrinolytic systems by neoplastic cells facilitates their invasiveness and metastases $[19,20]$. Thus, the extent of such activation has been associated with tumor stage and prognosis in some malignancies, such as breast, colorectal, and lung cancer [9-11]. Therefore, markers of clotting may preoperatively predict tumor progression and prognosis in GBC patients.

Various markers indicate an activated hemostatic system, such as thrombocytosis, hyperfibrinogenemia, and elevated D-dimer levels, and have been demonstrated in several cancer types, including gastric, colon, and pancreatic cancer [21-23]. Indeed, the current study also observed a significant difference between the cholecystitis control subjects and GBC patients in coagulation test findings, namely the PT, aPTT, TT, fibrinogen levels, and platelet counts, due to activation of the coagulation and fibrinolytic systems. Furthermore, in our GBC patient subgroup, advanced disease was associated with higher levels of fibrinogen.

Fibrinogen is an essential hemostatic factor that is converted to fibrin, a final product of the hemostatic pathway, by activated thrombin. Fibrinogen is synthesized in the liver and secreted into the circulation, and the levels of this acute-phase reactant increase in response to most forms of tissue injury, infection, or inflammation $[24,25]$. Recently, it was reported that the plasma fibrinogen levels was correlated with tumor size, depth of tumor invasion, and metastasis in patients with gastric cancer [26]. Moreover, other studies revealed that lymphatic and hematogenous metastases were greatly reduced in fibrinogen-deficient mice, which indicates a positive role for fibrinogen in the metastatic progression of cancer [27,28].

Surgical resection is the only effective treatment for GBC [29]. Thus, surgeons require precise preoperative assessment and tumor staging to correctly identify surgical options. Because of its nonspecific symptoms and highly invasive nature, GBC is often only detected when it has reached an advanced stage [30]. In the present study, we observed a positive relationship between hyperfibrinogenemia and TNM stage. In particular, hyperfibrinogenemia predicted tumor staging at a positive predictive rate of $92.7 \%$, indicating that hyperfibrinogenemia can be used as a preoperative indicator of advanced disease in GBC patients. Additionally, the majority of patients with early stage GBC have nonspecific symptoms or vague complaints that are easily confused with symptoms of benign gallbladder disease such as cholelithiasis. In some cases, the diagnosis of GBC has been missed at the time of routine cholecystectomy for benign disease. Stage $T_{1 b}$ and $T_{2}$ cases are often misdiagnosed intraoperatively, and these patients must undergo additional surgery to improve their survival. Based on our findings, we suggest that surgeons carefully observe the pathological lesion during surgery and perform a cryosection evaluation in gallbladder disease patients with preoperative hyperfibrinogenemia. Then, the surgical procedures should be suspended until the pathological diagnosis is established to prevent unnecessary surgical trauma to the patient.

Many recent studies have demonstrated that hyperfibrinogenemia, as a marker of coagulation and fibrinolytic activation, is a strong predictor of poor prognosis for gastrointestinal malignancy [22,23,26,31]. Using univariate analysis, our study revealed the significance of hyperfibrinogenemia, and multivariate analysis of survival emphasized the impact of hyperfibrinogenemia on GBC patient survival. In particular, patients with advanced stage disease tended to have decreased survival.

Although fibrinogen synthesis is significantly upregulated by inflammation [32], the molecular mechanisms responsible for changes in GBC metastasis and invasion have not been clearly elucidated. Thus, the present study sought to determine whether fibrinogen levels and GBC development have a cause-and-effect relationship, and whether hyperfibrinogenemia could therefore promote tumor development. In the present study, we showed that co-culture with highly concentrated fibrinogen increased GBC cell migration, invasion, and metastatic capacity, and induced EMT by increasing the expression of vimentin (a mesenchymal marker) and reducing expression of E-cadherin (an epithelial marker). EMT plays a central role in tumor progression. There is accumulating evidence that EMT confers migration, invasion, and metastatic capacity, and multidrug resistance to tumor cells $[33,34]$. Therefore, we believe that 
fibrinogen may contribute to cell migration by inducing the EMT.

\section{Conclusion}

Based on our findings, we suggest measuring the plasma fibrinogen levels preoperatively in new GBC patients to evaluate tumor progression and outcome. Furthermore, we conclude that fibrinogen enhances cell migration and invasion in vitro. However, our study was limited by its retrospective design and the small number of included patients. Thus, further studies of larger numbers of patients and prospective studies are required to confirm the present results.

\section{Abbreviations \\ GBC: Gallbladder cancer; PT: Prothrombin time; aPTT: Activated partial thromboplastin time; TT: Thrombin time; INR: International normalized ratio; ROC: Receiver operating characteristic curves analysis; OS: Overall survival; EMT: Epithelial-mesenchymal transitions; SEER: Surveillance, epidemiology, and end results; TNM: Tumor, node, metastasis; AJCC: American Joint Committee on Cancer; CBD: Common bile duct; qRT-PCR: Quantitative real-time PCR analysis; PPV: Positive predictive values; AUC: The area under the ROC curve; ALT: Glutamate pyruvate transaminase; AST: Glutamic oxalacetic transaminase; WBC: White blood cell; CEA: Carcino embryonic antigen.}

\section{Competing interest}

The authors declare no competing interest.

\section{Authors' contributions}

SYJ and WH were responsible for the experimental design. SYJ contributed to the execution of experiments, data statistics, and manuscript composition. $\mathrm{WH}, \mathrm{BRF}$, and WXS participated in performing the experiment and in the manuscript mapping and submission. DQ, CY, WXA, ZF, XSS, and LHF participated in the discussion and data interpretation. LML, MJS, and WWG conceived the study and revised the manuscript. LYB was responsible for the funding application and the supervision and management of the project. All authors have contributed to and approved the final manuscript.

\section{Acknowledgments}

This study was supported by the National Natural Science Foundation of China (No. 81172026, 81272402, 81301816, and 81172029), the National High Technology Research, and Development Program (863 Program) (No. 2012AA022606), the Foundation for Interdisciplinary research of Shanghai Jiao Tong University (No. YG2011ZD07), the Shanghai Science and Technology Commission Inter-governmental International Cooperation Project (No. 12410705900), the Shanghai science and technology commission medical-guiding project (No. 12401905800), the Program for Changjiang Scholars, the Natural Science Research Foundation of Shanghai Jiao Tong University School of Medicine (No. 13XJ10037), and the Leading Talent program of Shanghai and Specialized Research Foundation for the Ph. D Program of Higher Education-Priority Development Field (No. 20130073130014)

Received: 12 May 2014 Accepted: 30 July 2014

Published: 5 August 2014

\section{References}

1. Wu XS, Shi LB, Li ML, Ding Q, Weng H, Wu WG, Cao Y, Bao RF, Shu YJ, Ding QC, Mu JS, Gu J, Dong P, Liu YB: Evaluation of two inflammation-based prognostic scores in patients with resectable gallbladder carcinoma. Ann Surg Oncol 2014, 21(2):449-457.

2. $\quad$ Li M, Zhang S, Wang Z, Zhang B, Wu X, Weng H, Ding Q, Tan Z, Zhang N, Mu J, Yang J, Shu Y, Bao R, Ding Q, Wu W, Cao Y, Liu Y: Prognostic significance of nemo-like kinase (NLK) expression in patients with gallbladder cancer. Tumour Biol 2013, 34(6):3995-4000.
3. Li M, Zhang Z, Li X, Ye J, Wu X, Tan Z, Liu C, Shen B, Wang XA, Wu W, Zhou D, Zhang D, Wang T, Liu B, Qu K, Ding Q, Weng H, Ding Q, Mu J, Shu Y, Bao R, Cao Y, Chen P, Liu T, Jiang L, Hu Y, Dong P, Gu J, Lu W, Shi W, et al: Whole-exome and targeted gene sequencing of gallbladder carcinoma identifies recurrent mutations in the ErbB pathway. Nat Genet 2014, 46(8):872-876.

4. Luzzatto G, Schafer Al: The prethrombotic state in cancer. Semin Oncol 1990, 17(2):147-159.

5. Lopez Y, Paloma MJ, Rifon J, Cuesta B, Paramo JA: Measurement of prethrombotic markers in the assessment of acquired hypercoagulable states. Thromb Res 1999, 93(2):71-78.

6. Lyman $\mathrm{GH}$, Khorana AA: Cancer, clots and consensus: new understanding of an old problem. J Clin Oncol 2009, 27(29):4821-4826.

7. Dvorak HF: Thrombosis and cancer. Hum Pathol 1987, 18(3):275-284.

8. Amirkhosravi A, Meyer T, Amaya M, Davila M, Mousa SA, Robson T, Francis $J$ : The role of tissue factor pathway inhibitor in tumor growth and metastasis. Semin Thromb Hemost 2007, 33(7):643-652.

9. Blackwell $K$, Haroon Z, Broadwater G, Berry D, Harris L, lglehart JD, Dewhirst M, Greenberg C: Plasma D-dimer levels in operable breast cancer patients correlate with clinical stage and axillary lymph node status. J Clin Oncol 2000, 18(3):600-608.

10. Oya M, Akiyama Y, Okuyama T, Ishikawa H: High preoperative plasma Ddimer level is associated with advanced tumor stage and short survival after curative resection in patients with colorectal cancer. Jpn J Clin Oncol 2001, 31(8):388-394.

11. Taguchi O, Gabazza EC, Yasui H, Kobayashi T, Yoshida M, Kobayashi H: Prognostic significance of plasma D-dimer levels in patients with lung cancer. Thorax 1997, 52(6):563-565.

12. Bao RF, Shu YJ, Dong P, Gu J, Wu XS, Li ML, Weng H, Ding Q, Wu WG, Ding QC, Wu WG, Ding QC, Shen BY, Liu YB: [Change of coagulation in patients with gallbladder cancer and its clinical significance]. Zhonghua Wai Ke Za Zhi 2013, 51(12):1067-1070.

13. Edge SB, Compton CC: The American Joint Committee on Cancer: the 7th edition of the AJCC cancer staging manual and the future of TNM. Ann Surg Oncol 2010, 17(6):1471-1474.

14. Regimbeau JM, Fuks D, Bachellier P, Le Treut YP, Pruvot FR, Navarro F, Chiche L, Farges O: Prognostic value of jaundice in patients with gallbladder cancer by the AFC-GBC-2009 study group. Eur J Surg Oncol 2011, 37(6):505-512.

15. Wenguang $W$, Xuefeng $W$, Zhiping $Z$, Xiangsong $W$, Jianwei $W$, Songgang $L$, Yingbin L: Three-step method for lymphadenectomy in gastric cancer surgery: a single institution experience of 120 patients. J Am Coll Surg 2011, 212(2):200-208.

16. Falanga A: Thrombophilia in cancer. Semin Thromb Hemost 2005, 31(1):104-110.

17. Tas F, Kilic L, Serilmez M, Keskin S, Sen F, Duranyildiz D: Clinical and prognostic significance of coagulation assays in lung cancer. Respir Med 2013, 107(3):451-457.

18. Gunji Y, Gorelik E: Role of fibrin coagulation in protection of murine tumor cells from destruction by cytotoxic cells. Cancer Res 1988, 48(18):5216-5221.

19. Kolodziejczyk J, Ponczek MB: The role of fibrinogen, fibrin and fibrin(ogen) degradation products (FDPs) in tumor progression. Contemp Oncol (Pozn) 2013, 17(2):113-119.

20. Zheng S, Shen J, Jiao Y, Liu Y, Zhang C, Wei M, Hao S, Zeng X: Platelets and fibrinogen facilitate each other in protecting tumor cells from natural killer cytotoxicity. Cancer Sci 2009, 100(5):859-865.

21. Liu L, Zhang X, Yan B, Gu Q, Jiao J, Sun D, Wang N, Yue X: Elevated plasma D-dimer levels correlate with long term survival of gastric cancer patients. PLoS One 2014, 9(3):e90547.

22. Son HJ, Park JW, Chang HJ, Kim DY, Kim BC, Kim SY, Park SC, Choi HS, Oh $\mathrm{JH}$ : Preoperative plasma hyperfibrinogenemia is predictive of poor prognosis in patients with nonmetastatic colon cancer. Ann Surg Oncol 2013, 20(9):2908-2913.

23. Wang H, Gao J, Bai M, Liu R, Li H, Deng T, Zhou L, Han R, Ge S, Huang D, Ba $Y$ : The pretreatment platelet and plasma fibrinogen level correlate with tumor progression and metastasis in patients with pancreatic cancer. Platelets 2014, 25(5):382-387.

24. Mosesson MW: Fibrinogen and fibrin structure and functions. J Thromb Haemost 2005, 3(8):1894-1904.

25. Tennent GA, Brennan SO, Stangou AJ, O'Grady J, Hawkins PN, Pepys MB: Human plasma fibrinogen is synthesized in the liver. Blood 2007, 109(5):1971-1974. 
26. Lee JH, Ryu KW, Kim S, Bae JM: Preoperative plasma fibrinogen levels in gastric cancer patients correlate with extent of tumor. Hepatogastroenterol 2004, 51(60):1860-1863.

27. Palumbo JS, Kombrinck KW, Drew AF, Grimes TS, Kiser JH, Degen JL, Bugge TH: Fibrinogen is an important determinant of the metastatic potential of circulating tumor cells. Blood 2000, 96(10):3302-3309.

28. Palumbo JS, Potter JM, Kaplan LS, Talmage K, Jackson DG, Degen JL: Spontaneous hematogenous and lymphatic metastasis, but not primary tumor growth or angiogenesis, is diminished in fibrinogen-deficient mice. Cancer Res 2002, 62(23):6966-6972.

29. Yang XW, Yang J, Li L, Man XB, Zhang BH, Shen F, Wu MC: Analysis of the relationships between clinicopathologic factors and survival in gallbladder cancer following surgical resection with curative intent. PLoS One 2012, 7(12):e51513.

30. Grundmann RT, Meyer F: [Gender-specific influencing factors on incidence, risk factors and outcome of carcinoma of the liver, gallbladder, extrahepatic bile duct and pancreas]. Zentralbl Chir 2014, 139(2):184-192.

31. Kinoshita A, Onoda H, Imai N, Iwaku A, Oishi M, Tanaka K, Fushiya N, Koike K, Nishino H, Matsushima M, Tajiri H: Elevated plasma fibrinogen levels are associated with a poor prognosis in patients with hepatocellular carcinoma. Oncology 2013, 85(5):269-277.

32. Whelton SP, Narla V, Blaha MJ, Nasir K, Blumenthal RS, Jenny NS, Al-Mallah $\mathrm{MH}$, Michos ED: Association between resting heart rate and inflammatory biomarkers (high-sensitivity C-reactive protein, interleukin-6, and fibrinogen) (from the Multi-Ethnic Study of Atherosclerosis). Am J Cardiol 2014, 113(4):644-649.

33. Romano S, Staibano S, Greco A, Brunetti A, Nappo G, llardi G, Martinelli R, Sorrentino A, Di Pace A, Mascolo M, Bisogni R, Scalvenzi M, Alfano B, Romano MF: FK506 binding protein 51 positively regulates melanoma stemness and metastatic potential. Cell Death Dis 2013, 4:e578.

34. He L, Zhou X, Qu C, Hu L, Tang Y, Zhang Q, Liang M, Hong J: Musashi2 predicts poor prognosis and invasion in hepatocellular carcinoma by driving epithelial-mesenchymal transition. J Cell Mol Med 2014, 18(1):49-58.

doi:10.1186/1471-2407-14-566

Cite this article as: Shu et al: Clinical and prognostic significance of preoperative plasma hyperfibrinogenemia in gallbladder cancer patients following surgical resection: a retrospective and in vitro study. BMC Cancer 2014 14:566.

\section{Submit your next manuscript to BioMed Central and take full advantage of:}

- Convenient online submission

- Thorough peer review

- No space constraints or color figure charges

- Immediate publication on acceptance

- Inclusion in PubMed, CAS, Scopus and Google Scholar

- Research which is freely available for redistribution

Submit your manuscript at www.biomedcentral.com/submit
C Biomed Central 